\title{
BORIS LYON-CAEN, Balzac e la lotta di posizione
}

\section{Marco Stupazzoni}

\section{CpenEdition \\ Journals}

\section{Edizione digitale}

URL: http://journals.openedition.org/studifrancesi/16521

DOI: 10.4000/studifrancesi. 16521

ISSN: 2427-5856

\section{Editore}

Rosenberg \& Sellier

\section{Edizione cartacea}

Data di pubblicazione: 1 juillet 2019

Paginazione: 174

ISSN: 0039-2944

\section{Notizia bibliografica digitale}

Marco Stupazzoni, «BorIS Lyon-CaEn, Balzac e la lotta di posizione», Studi Francesi [Online], 187 (LXIII | I) | 2019, online dal 01 juillet 2019, consultato il 25 janvier 2021. URL: http://journals.openedition.org/ studifrancesi/16521; DOI: https://doi.org/10.4000/studifrancesi.16521

Questo documento è stato generato automaticamente il 25 janvier 2021.

\section{(c) (†)}

Studi Francesi è distribuita con Licenza Creative Commons Attribuzione - Non commerciale - Non opere derivate 4.0 Internazionale. 


\title{
BORIS LYON-CAEN, Balzac e la lotta di posizione
}

\author{
Marco Stupazzoni
}

\section{NOTIZIA}

BORIS LYON-CAEN, Balzac e la lotta di posizione, in I personaggi minori. Funzioni e metamorfosi di una tipologia del romanzo moderno, a cura di Stefania Sbarra, Pisa, Pacini Editore, 2017, «I Libri dell'Associazione Sigismondo Malatesta. Studi di letteratura comparata (seconda serie)» 24, pp. 85-98.

1 Nella Comédie humaine e, in particolare, nel corpus relativamente circoscritto di romanzi su cui l'A. concentra la sua attenzione, le strategie del matrimonio «(dis)organizzano il sistema dei personaggi e scatenano una guerra di posizione senza pari - rendendo udibile e visibile, in modo esemplare, il bisogno o la necessità di nuove configurazioni» (p.90). Dal punto di vista tematico-narrativo e storico, le figure secondarie analizzate, lontane dal riflettere strutture e ruoli sociali gerarchicamente fissi, incarnano l'aspirazione degli esseri socialmente minori a una "promozione attanziale» (p. 89) e contribuiscono a determinare, nel loro divenire, le dinamiche informi delle strutture sociali. In questo senso, osserva l'A., il personaggio minore balzachiano è «questo operatore, questo motore a combustione del legame sociale incessantemente tessuto e allentato dal romanzo o nel romanzo» (p. 95). 